\title{
THE ACTION OF TRIETHYLCHOLINE ON THE PERISTALTIC REFLEX OF THE GUINEA-PIG ILEUM
}

\author{
BY \\ D. J. BOULLIN* \\ From the Department of Pharmacology and Therapeutics, Queen's College, Dundee \\ (Received May 15, 1963) \\ The action of triethylcholine on the peristaltic reflex of the guinea-pig isolated ileum has \\ been studied. When perfused through the lumen in low concentrations triethylcholine \\ first stimulated and then inhibited peristalsis. High concentrations gradually inhibited or \\ abolished the reflex without prior stimulation. These inhibitory effects were reversed by \\ choline, in the continued presence of triethylcholine. Similar responses followed application \\ of triethylcholine to the serosal surface of the gut, except that high concentrations produced \\ an immediate abolition of peristalsis which was not restored by choline. It is suggested \\ that the effects of intraluminal triethylcholine are due either to enhancement of acetylcholine \\ release or to reduction of acetylcholine synthesis, or to a combination of these factors, and \\ that the results are evidence that acetylcholine is a humoral transmitter involved in the \\ initiation of peristalsis.
}

The work described in this paper was undertaken primarily to obtain information concerning the nature of the transmitter or transmitters responsible for initiating the peristaltic reflex. Acetylcholine can be released from mammalian intestine (for references see Harry, 1962), and has been proposed as the humoral transmitter at cholinergic neurones involved in the peristaltic reflex pathway (Ambache, 1951). Therefore the action of the triethyl analogue of choline, triethyl(2-hydroxyethyl)ammonium, which may act by inhibiting synthesis of acetylcholine (Bowman \& Rand, 1961a, b), on the peristaltic reflex was of considerable interest.

\section{METHODS}

Animals. Adult guinea-pigs (weight 350 to $550 \mathrm{~g}$ ) were used.

Peristalsis. This was recorded isotonically in vitro using the method of Bülbring, Crema \& Saxby (1958). Portions of ileum, 45 to $60 \mathrm{~cm}$ from the pyloric sphincter, were suspended in a $200 \mathrm{ml}$. bath in Tyrode solution (containing $2 \mathrm{~g} / \mathrm{l}$. of glucose) gassed with $95 \%$ oxygen and $5 \%$ carbon dioxide. In all experiments a pressure of $20 \mathrm{~mm}$ of water was applied to the intestinal lumen to elicit the peristaltic reflex.

Drugs. Triethylcholine chloride, acetylcholine chloride and choline chloride were used. Weights of triethylcholine and choline refer to the salt, weights of acetylcholine to the base.

\section{RESULTS}

Bülbring \& Lin (1958) and Bülbring \& Crema (1958) showed that the peristaltic reflex of the guinea-pig isolated ileum is extremely active. This has been confirmed

* Present address: Laboratory of Chemical Pharmacology, National Heart Institute, National Institutes of Health, Bethesda, Maryland, U.S.A. 
here. The volume of fluid expelled from a length of gut was measured over a period, usually 10 to $30 \mathrm{~min}$, and expressed as $\mathrm{ml} . / \mathrm{hr}$; this is termed the " transport rate." The control transport rate varied from 73 to $280 \mathrm{ml}$./ hr (mean 182, standard error \pm $15.2 \mathrm{ml} . / \mathrm{hr}$, nineteen experiments); Bülbring \& Lin (1958) found a mean value of $100 \mathrm{ml} . / \mathrm{hr}$, using isometric recording of peristalsis.

In the absence of drugs, peristalsis continued without any large diminution in transport rate for up to $4 \mathrm{hr}$. The rate of peristalsis usually increased during the first hour, and the maximal transport rate was then maintained for up to $3 \mathrm{hr}$, followed by a slight decline in rate during the fourth hour (mean decrease $13.5 \%$, four experiments).

Intraluminal perfusion with solutions of triethylcholine. Triethylcholine added to the fluid passing through the lumen produced two effects. Low concentrations ( 5 to $20 \mu \mathrm{g} / \mathrm{ml}$.) increased peristalsis, while higher concentrations (up to $200 \mu \mathrm{g} / \mathrm{ml}$.) abolished the reflex. Stimulation of peristalsis is shown in Fig. 1a. There was an increase in peristalsis during the first $10 \mathrm{~min}$ of perfusion with triethylcholine, with a rise in transport rate from 204 to $260 \mathrm{ml} . / \mathrm{hr}$ ( $27.5 \%$ increase), associated with an increase in the frequency of reflex contractions. Subsequently the transport rate declined to $215 \mathrm{ml} . / \mathrm{hr} 40 \mathrm{~min}$ after the start of the perfusion with triethylcholine (Fig. 1b). At this time there was also an increase in the rise in intraluminal pressure

(a)

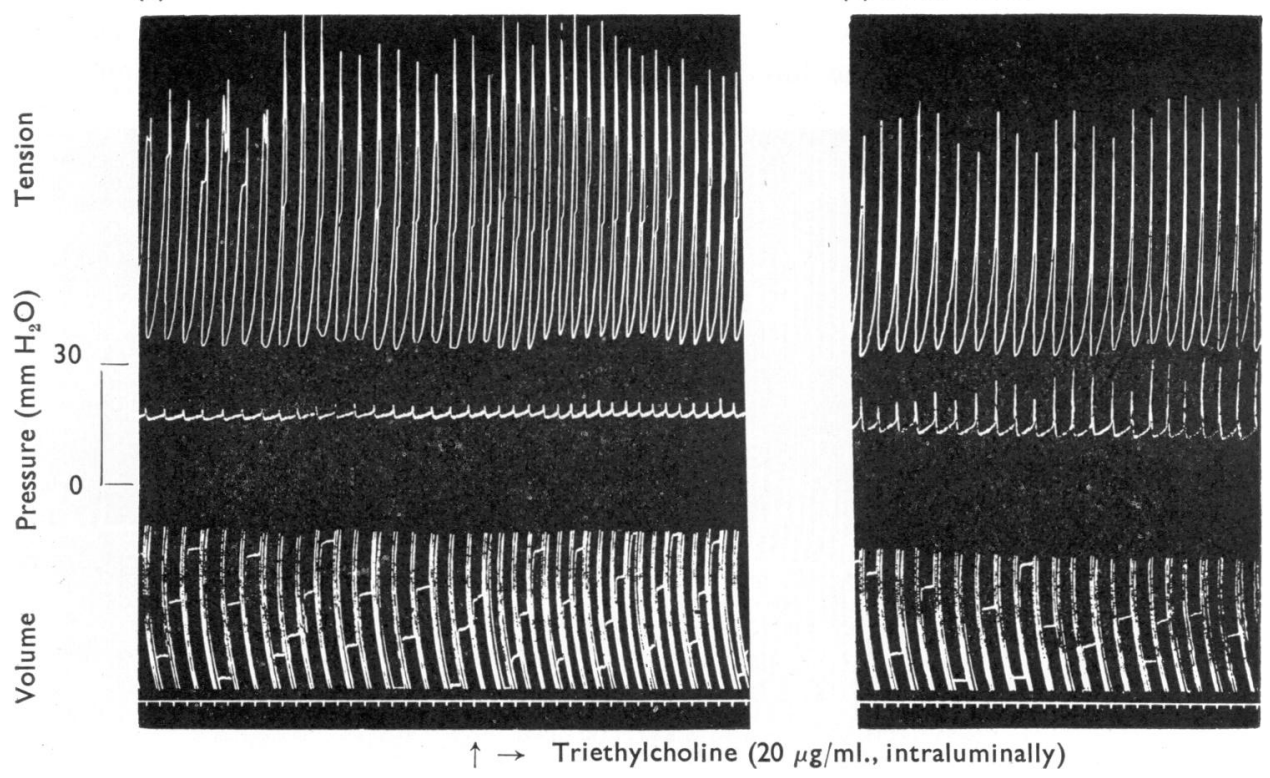

Fig. 1. Effect of triethylcholine on the peristalsis of the guinea-pig isolated ileum. From above down: longitudinal tension, intraluminal pressure, volume of fluid expelled from the intestinal lumen (each vertical line indicates $1 \mathrm{ml}$.) and time signal $(30 \mathrm{sec})$. At the arrow triethylcholine $(20 \mu \mathrm{g} / \mathrm{ml}$.) was perfused through the lumen until the end of $(b)$. The interval between (a) and (b) was $18 \mathrm{~min}$. 
recorded, with each reflex contraction, at the oral end of the gut. This is clearly seen by comparing Fig. $1 a$ with Fig. $1 b$. The size of this pressure rise was determined by the degree of occlusion of the intestinal lumen, produced by the contraction of the circular muscle at the beginning of the emptying phase of the peristaltic reflex. When the proximal end of the gut was completely occluded by a strong contraction of the circular muscle, little or no fluid passed in an oral direction during the propulsive phase of peristalsis, so there was little or no rise in pressure, and the reflex would have high propulsive efficiency (see Bülbring \& Lin, 1958). On the other hand, when the propulsive contractions were weaker and the lumen was not completely occluded, fluid was ejected both in the oral and the aboral directions with a big rise in intraluminal pressure, measured at the oral end, and the reflex would be less efficient in causing propulsion. Fig. 1 indicates that triethylcholine reduced the propulsive efficiency of peristalsis.

High intraluminal concentrations of triethylcholine inhibited or abolished peristalsis without prior stimulation. This was shown in the experiment illustrated by Fig. 2. The first effect, which appeared after about $5 \mathrm{~min}$, was a rise in intraluminal pressure indicating a decrease in propulsive efficiency. This was followed by a rise in the threshold pressure at which the reflex was elicited, until finally propulsive waves were almost abolished $27 \mathrm{~min}$ after the start of the perfusion with triethylcholine. However, frequent contractions of the longitudinal muscle of the gut continued.

When peristalsis had been inhibited and propulsion of fluid abolished by triethylcholine, small volumes of fluid flowed through the lumen passively. Thus choline could be introduced into the lumen, in the continued presence of triethylcholine,

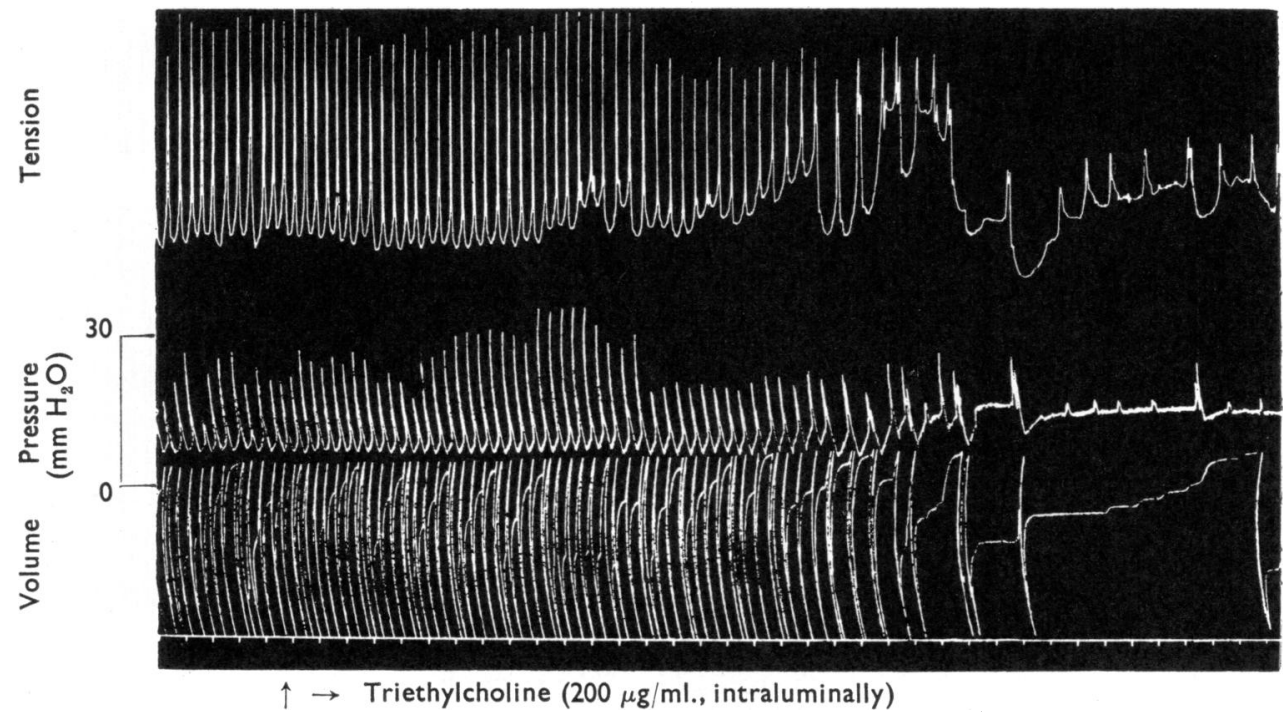

Fig. 2. Inhibition of peristalsis by triethylcholine. Records as for Fig. 1, except time signal, which is $1 \mathrm{~min}$. At the arrow triethylcholine $(200 \mu \mathrm{g} / \mathrm{ml}$.) was perfused through the lumen until the end of the record; after $27 \mathrm{~min}$ active propulsive movements were abolished. 
without mechanical disturbance of the gut. When this was done, peristaltic activity was gradually restored. This is shown in Fig. 3, which illustrates a continuation of the experiment of Fig. 2. When choline $(1 \mathrm{mg} / \mathrm{ml}$.) was introduced, there was

(a)

$3^{\prime}$

$100^{\prime}$

(b)

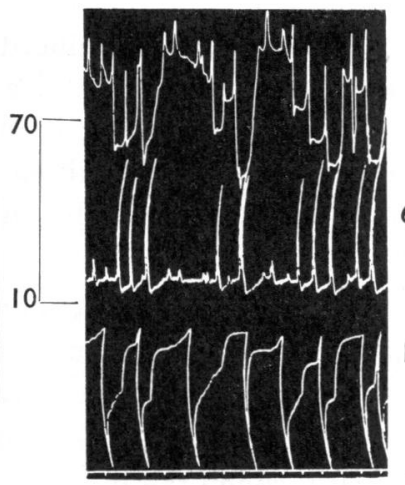

$\uparrow \rightarrow$ Triethylcholine $(200 \mu \mathrm{g} / \mathrm{ml}$., intraluminally)

$\uparrow \rightarrow$ Choline ( $1 \mathrm{mg} / \mathrm{ml}$., intraluminally) $265^{\prime}$

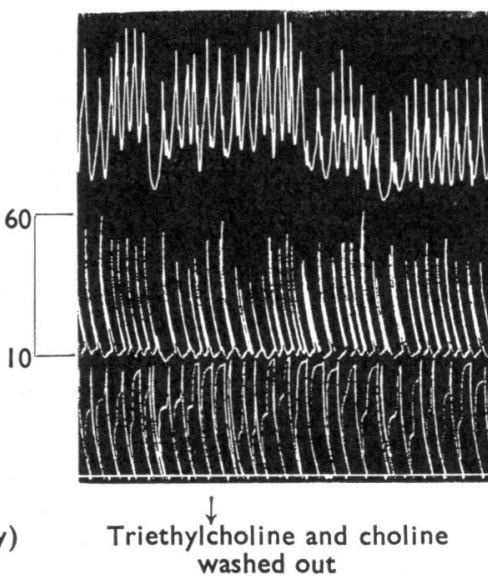

Fig. 3. Restoration of peristalsis by choline, following inhibition by triethylcholine, in the continuation of the experiment shown in Fig. 2; records as for Fig. 2. (a): at the arrow choline $(1 \mathrm{mg} / \mathrm{ml}$.) was added to the perfusion fluid (already containing triethylcholine, $200 \mu \mathrm{g} / \mathrm{ml}$.); $(b): 100$ min later; $(c): 265$ min after $(a)$. At the arrow perfusion of both triethylcholine and choline was stopped. Times above records in min from start of perfusion with choline.

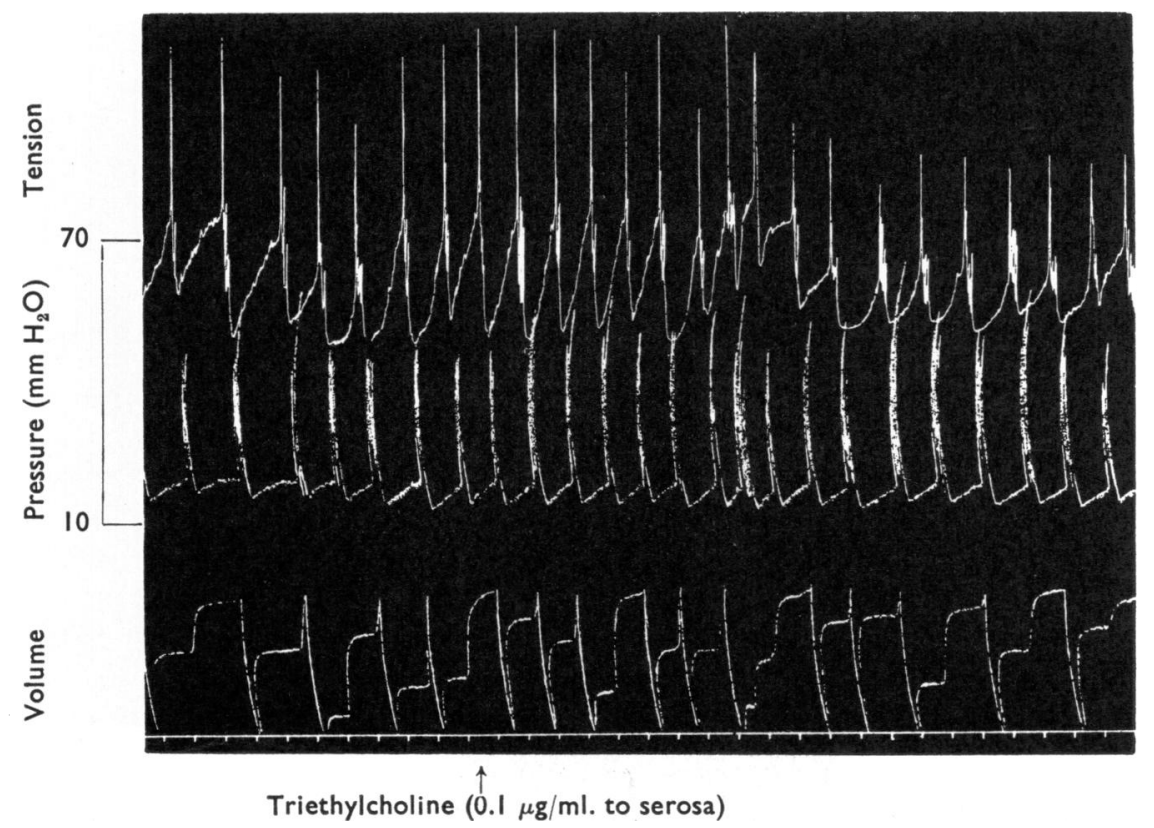

Fig. 4. Effect of serosal application of triethylcholine on peristalsis. Records as for Fig. 2. At the arrow $20 \mu \mathrm{g}$ of triethylcholine was added to the bath (final concentration $0.1 \mu \mathrm{g} / \mathrm{ml}$.). 
no immediate effect and passive flow continued (Fig. 3a). However, 65 min later the first peristaltic contraction of the gut occurred and, $100 \mathrm{~min}$ after the addition of choline, peristaltic activity was restored, though with reduced propulsive efficiency (Fig. 3b). Finally, $265 \mathrm{~min}$ after the addition of choline to the perfusion fluid, peristalsis reached a maximal value (Fig. $3 c$ ). The transport rate before addition of triethylcholine was $160 \mathrm{ml} . / \mathrm{hr}$. This rate was reduced to a minimum of between 4 and $15 \mathrm{ml} . / \mathrm{hr}$ by triethylcholine and was restored to a maximum of $84 \mathrm{ml} . / \mathrm{hr}$ by choline, that is to $52.5 \%$ of the original value. It is important to realize that by this time the experiment had been in progress for about $5 \mathrm{hr}$. The mean recovery of the transport rate due to choline $(1 \mathrm{mg} / \mathrm{ml}$.), after inhibition by triethylcholine, was $45.6 \%$ for six experiments.

When perfusion with both triethylcholine and choline was stopped, there was not immediate change in peristalsis. If intraluminal choline was alone perfused in the same concentration there was no stimulation of reflex activity.

Serosal application of triethylcholine. The effects of this procedure were similar to those of triethylcholine perfused through the lumen. That is low concentrations

(a)

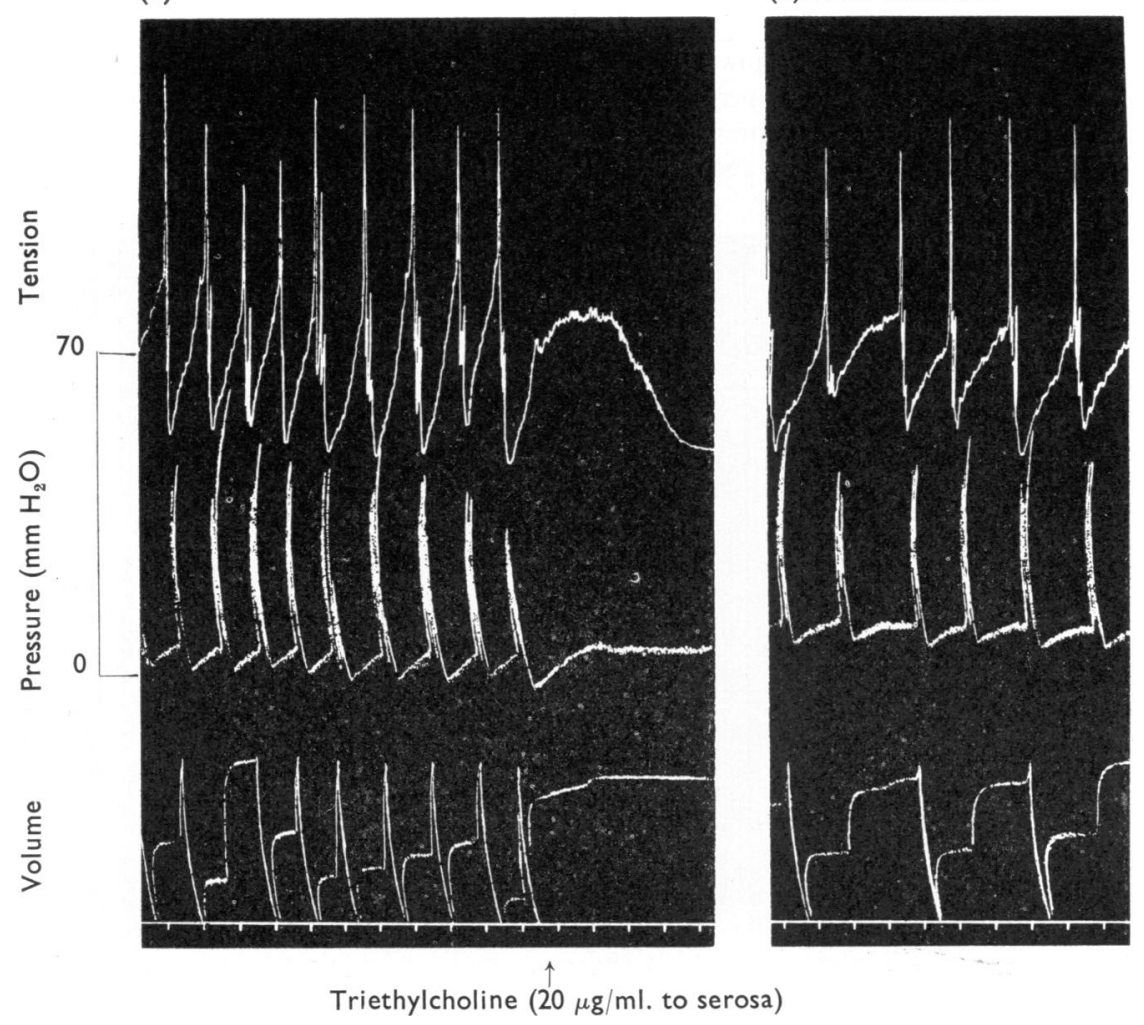

Fig. 5. Effect of serosal application of triethylcholine on peristalsis. Records as for Fig. 2. $(a)$ : at the arrow, $20 \mu \mathrm{g} / \mathrm{ml}$. of triethylcholine was added to the bath; between $(a)$ and $(b)$ the bath was washed out three times; $(b): 12$ min later. 
of the drug ( 0.1 to $5 \mu \mathrm{g} / \mathrm{ml}$.) first stimulated and then inhibited peristalsis, while high concentrations ( 5 to $50 \mu \mathrm{g} / \mathrm{ml}$ ) ) inhibited peristalsis without prior stimulation. Initial stimulation is shown in Fig. 4. The stimulation was followed after about $12 \mathrm{~min}$ by slow development of inhibition.

The most prominent effects were evident when high concentrations of triethylcholine were used. Then peristalsis was abolished immediately the drug was added to the bath (Fig. 5a). Peristalsis was readily restored by washing out the drug (Fig. 5b), but it was not restored by serosal application of choline, since this procedure produced intestinal spasm so that fluid did not pass through the lumen of the gut.

\section{DISCUSSION}

Bowman \& Rand (1961a, b) showed that triethylcholine prevented transmission at the mammalian neuromuscular junction, and considered that this effect was due to reduced synthesis of acetylcholine, possibly caused by inhibition of choline acetylase. On the other hand, Roberts (1962) showed that triethylcholine enhanced acetylcholine release in frog skeletal muscle. He considered that the effects observed by Bowman $\&$ Rand were due, not to a reduction in synthesis of acetylcholine, but to a shortage of transmitter as a consequence of the inability of the acetylcholine-synthesizing mechanism to keep pace with an increased output. Other pharmacological actions of triethylcholine include a curare-like effect (Roberts, 1962; Bowman, Hemsworth \& Rand, 1962) and anticurare and anticholinesterase actions (Bowman et al., 1962).

While the initial stimulation of peristalsis produced by serosal application of triethylcholine may have been due to enhanced release of acetylcholine, the inhibition of the peristaltic reflex seen with high concentrations of the drug on the serosa does not appear to have been due to interference with synthesis or release of acetylcholine, since the effect was nearly instantaneous. On the other hand, the most plausible explanation of the inhibition of peristalsis caused by intraluminal triethylcholine is that it was due to failure of released acetylcholine to act as a transmitter, either at intramural ganglionic sites or at nerve terminals. This explanation is supported by the pattern of development of the inhibition, which was similar to that for skeletal muscle, being slow in onset, and therefore consistent with the idea that acetylcholine stores had to be depleted before the inhibitory effects of triethylcholine were seen. Further, the remarkable restoration, by choline, of the peristaltic reflex after it had been abolished by triethylcholine suggested that normal rates of acetylcholine synthesis were renewed by a flooding of the enzyme choline acetylase with substrate, namely choline. While the initial stimulation of peristalsis due to intraluminal triethylcholine could have been due to enhancement of release of acetylcholine, this explanation can hardly account for the effects of choline. This has already been pointed out by Bowman et al. (1962).

It is not possible to deduce from the present experiments the precise mechanism of action of triethylcholine, although it is suggested that some of the observed effects may well be due both to enhancement of release and to impairment of synthesis of acetylcholine. Whether this explanation is correct, the results reported here are 
evidence that acetylcholine is concerned at some stage in the nervous pathways involved in the initiation of the peristaltic reflex.

Triethylcholine was kindly supplied by Dr J. M. Simister of Ward, Blenkinsop \& Co.

\section{REFERENCES}

AMBACHE, N. (1951). Unmasking, after cholinergic paralysis by botulinum toxin, of a reversed action of nicotine on mammalian intestine, revealing the probable presence of local inhibitory ganglion cells in the enteric plexuses. Brit. J. Pharmacol., 6, 51-67.

Bowman, W. C., Hemsworth, B. A. \& RAND, M. J. (1962). Triethylcholine compared with other substances affecting neuromuscular transmission. Brit. J. Pharmacol., 19, 198-218.

BOWmaN, W. C. \& RAND, M. J. (1961a). The triethyl analogue of choline and neuromuscular transmission. Lancet, i, 480-481.

BowmaN, W. C. \& RAND, M. J. (1961b). Actions of triethylcholine on neuromuscular transmission. Brit. J. Pharmacol., 17, 176-195.

BÜlbring, E. \& CREMA, A. (1958). Observations concerning the action of 5-hydroxytryptamine on the peristaltic reflex. Brit. J. Pharmacol., 13, 444-457.

BUtlbring, E., Crema, A. \& SAXBY, O. B. (1958). A method for recording peristalsis in isolated intestine. Brit. J. Pharmacol., 13, 440-443.

BÜLBRING, E. \& LIN, R. C. Y. (1958). The effect of intraluminal application of 5-hydroxytryptamine and 5-hydroxytryptophan on peristalsis; the local production of 5-hydroxytryptamine and its release in relation to intraluminal pressure and propulsive activity. J. Physiol. (Lond.), 140, $381-407$.

HARRY, J. (1962). Effect of cooling, local anaesthetic compounds and botulinum toxin on the responses of an acetylcholine output from the electrically transmurally stimulated isolated guinea-pig ileum. Brit. J. Pharmacol., 19, 42-55.

RoBERTS, D. V. (1962). Neuromuscular activity of the triethyl analogue of choline in the frog. J. Physiol. (Lond.), 160, 94-105. 